\title{
CORRELATION OF NLR AND PROCALCITONIN WITH SECONDARY INFECTION, SEVERITY, AND MORTALITY INCOVID-19
}

\author{
Grace Leonora Trisna ${ }^{\mathrm{a}}$, Hamzah $^{\mathrm{b} *}$, Lucky Andriyanto ${ }^{\mathrm{b}}$, Prihatma Kriswidyatomo ${ }^{\mathrm{b}}$, \\ ArieUtariani $^{\mathrm{b}}$

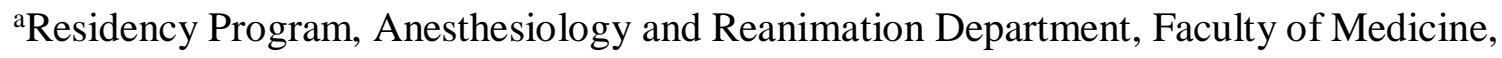 \\ Airlangga University, Dr Soetomo Hospital, Surabaya, Indonesia \\ ${ }^{\mathrm{b}}$ Anesthesiology and Reanimation Department, Faculty of Medicine, Airlangga University, \\ Dr Soetomo Hospital, Surabaya, Indonesia \\ *Email: anestesi.hamzah@gmail.com
}

\begin{abstract}
This was analytic observasional study with retrospective cohort design. Data collection was done in Dr Soetomo Hospital's isolation rooms during July-December 2020 period. Serial NLR and procalcitonin were recorded first on hospital admission, on highest value of NLR/procalcitonin, and then on 24 hours before hospital discharge. Secondary infection was recorded from positive cultures during treatment. Severity was measured by SOFA score and WHO. Mortality data were recorded from medical record. Spearman test, Mann-Whitney test, and ROC curve analysis were used in statistical analysis. There were 119 patients included in this study. Mortality rate was 38,6\%. Secondary infection rate was 21,8 . There were significant correlations between NLR and severity $(\mathrm{p}<0,001)$. NLR cutoff value as severe-critical illness predictors was $>6,82$. There were significant NLR differences between mortality groups $(\mathrm{p}<0,001)$. NLR cutoff value as mortality predictors was $>12,75$. There were significant correlations between procalcitonin and severity $(\mathrm{p}<0,001)$. Procalcitonin cutoff value as severe-critical illness predictors was $>0,145 \mathrm{ng} / \mathrm{ml}$. There were significant procalcitonin differences between mortality groups $(\mathrm{p}<0,001)$. Procalcitonin cutoff values as mortality predictors were $>0,285 \mathrm{ng} / \mathrm{ml}$. There were significant NLR and procalcitonin difference in patients with secondary infection. NLR and procalcitonin are useful as severity and mortality predictors in COVID-19.
\end{abstract}

Keywords : COVID-19, Mortality, NLR, procalcitonin, severity, SOFA Score

\section{INTRODUCTION}

Coronavirus disease 2019 (COVID-19) is an ongoing global pandemic which caused by Severe Acute Respiratory Syndrome Coronavirus-2 (SARS-CoV-2). It was first identified from an outbreak of pneumonia from previously unknown cause in the city of Wuhan, the capital of China's Hubei province on December 2019. The World Health Organization (WHO) declared a Public Health Emergency of International Concern on 30 January 2020 and a pandemic on 11 March 2020. Globally, as of 23 December 2021, there have been 276 million confirmed cases, including 5.3 million deaths, reported to WHO (1). Approximately 20,3\% of hospitalized patients required intensive care treatment because of ARDS, acute cardiac injury, acute kidney 
Viral infection in respiratory system is associated with increased risk of bacterial infection. Approximately 40-50 million people died in influenza pandemic in 1918, mostly caused by secondary bacterial infection which is Streptococcus pneumoniae (3). During H1N1 outbreak in $2009,30 \%$ of critical patients were diagnosed with bacterial pneumonia or bacteriemia 72 hours after ICU admission (4).

Neutrophil-lymphocyte ratio (NLR) is derived from calculation of absolute neutrophil count divided by absolute lymphocyte count. It is an inexpensive parameter and mostly available in every hospital. NLR will increase in inflammation process (5).

Procalcitonin is precursor of calcitonin. Procalcitonin production and release markedly increase in bacterial infection, triggered by IL-1 $\beta$, TNF- $\alpha$ and IL-6 (6). This study aims were to evaluate the role of NLR and procalcitonin in predicting secondary infection, severity, and mortality of COVID-19.

\section{METHODS}

This retrospective cohort study was conducted in July 2020 - December 2020 at COVID-19 Isolation Room Dr. Soetomo Hospital Surabaya. Ethical clearance was issued by Clinical Research Unit Dr. Soetomo Hospital Surabaya. The study population was COVID-19 confirmed patients who were admitted to Isolation Room Dr. Soetomo Hospital Surabaya and met the inclusion and exclusion criteria.

Inclusion criteria were adults ( $\geq 18$ years old), COVID-19 confirmed with positive RTPCR results from nasopharyngeal swab and gave informed consent. Exclusion criteria were history of cancer or chemotherapy, history of autoimmune disease or receiving immunosuppressant therapy, history of thyroid disease, pregnant women and in the puerperium period, history of trauma or in perioperative period, HIV patients. Drop-out criteria were any treatment refusal and lysis or incomplete blood samples.

Sampling method was total sampling from medical records. Samples that met inclusion and exclusion criteria were recorded for identity, demography data, and clinical conditions. Serial NLR and procalcitonin were recorded first on hospital admission in Isolation Room (NLR/PCT 1), second on highest value of NLR/procalcitonin (NLR/PCT 2), and then on 24 hours before hospital discharge (NLR/PCT 3). Secondary infection was recorded from positive blood, urine, or sputum cultures during treatment. Severity was measured by SOFA score (7) and WHO classification (8) - mild, moderate, severe, and critical. Mortality data were recorded among this groups. Later, the data will be processed with the SPSS Statistic Ver 25.

Characteristics of research subjects presented in descriptive statistical analysis. The significance of differences between groups were analyzed using a comparative test according to the type of data (Chi Square, Fisher's Exact, or Mann-Whitney test). Significant $p$ value was $<0,05$. Correlation between NLR or procalcitonin levels with SOFA score or severity groups were analyzed using Spearman test. NLR and procalcitonin levels difference between mortality or secondary infection groups were analyzed using Mann-Whitney test. Any parameters which had a significant difference was analyzed with ROC curve to get the cut off value. 


\section{RESULTS}

\section{Characteristics of Research Subjects}

Total of 119 patients met inclusion and exclusion criteria of this study. Subjects characteristics based on severity at hospital admission were summarized in Table 1. Patients in critical group were mostly male $(79,6 \%)$ and older. The most common comorbidities in our patients were diabetes and hypertension, with greater percentage in critical groups. Critical groups had higher mortality rate, SOFA score, ICU admission, mechanical ventilator requirements, and complications.

Table 1. Subjects Characteristics Based on Severity At Hospital Admission

\begin{tabular}{|c|c|c|c|c|c|}
\hline Characteristics & $\begin{array}{l}\text { Mild } \\
\text { N=20 }\end{array}$ & $\begin{array}{c}\text { Moderate } \\
\mathrm{N}=15\end{array}$ & $\begin{array}{c}\text { Severe } \\
\mathbf{N}=\mathbf{3 0}\end{array}$ & $\begin{array}{c}\text { Critical } \\
N=54\end{array}$ & $\mathbf{p}$ \\
\hline Age (Years)* & $\begin{array}{l}42,5(29,25- \\
52)\end{array}$ & $52(41-55)$ & $\begin{array}{l}54(44,75- \\
61,25)\end{array}$ & $53(45-60)$ & $0,022^{\mathrm{a}}$ \\
\hline Gender & & & & & $0,015^{\mathrm{b}}$ \\
\hline Male & $9(45 \%)$ & $10(66,7 \%)$ & $16(53,3 \%)$ & $43(79,6 \%)$ & \\
\hline Female & $11(55 \%)$ & $5(33,3 \%)$ & $14(46,7 \%)$ & $11(20,4 \%)$ & \\
\hline BMI & & & & & $0,412^{\mathrm{b}}$ \\
\hline$<25$ & $12(60 \%)$ & $6(40 \%)$ & $11(36,7 \%)$ & $23(42,6 \%)$ & \\
\hline$\geq 25$ & $8(40 \%)$ & $9(60 \%)$ & $19(63,3 \%)$ & $31(57,4 \%)$ & \\
\hline \multicolumn{6}{|l|}{ Comorbidities } \\
\hline Diabetes & $4(20 \%)$ & $5(33,3 \%)$ & $14(46,7 \%)$ & $20(37 \%)$ & $0,288^{\mathrm{b}}$ \\
\hline Hypertension & $4(20 \%)$ & $2(13,3 \%)$ & $12(40 \%)$ & $26(48,1 \%)$ & $0,028^{\mathrm{b}}$ \\
\hline Others & $1(5 \%)$ & $1(6,7 \%)$ & $2(6,6 \%)$ & $12(22,2 \%)$ & $0,093^{\mathrm{b}}$ \\
\hline $\begin{array}{l}\text { Symptoms } \\
\text { duration (days) } \\
*\end{array}$ & $5(3-7)$ & $7(5-10)$ & $7(5-9)$ & $7(5-10,5)$ & $0,082^{\mathrm{a}}$ \\
\hline $\begin{array}{l}\text { Length of stay } \\
\text { (LOS) (days)* }\end{array}$ & $\begin{array}{l}13,5(8,5- \\
22,5)\end{array}$ & $15(11-24)$ & $17(9,5-22)$ & $13,5(6-24)$ & $0,831^{\mathrm{a}}$ \\
\hline $\begin{array}{l}\text { SOFA score D- } \\
0^{*}\end{array}$ & $0(0-0)$ & $1(1-2)$ & $3(2-3)$ & $5(4-5,25)$ & $<0,001^{\mathrm{a}}$ \\
\hline $\begin{array}{l}\text { Highest SOFA } \\
\text { score } *\end{array}$ & $0(0-1)$ & $2(1-3)$ & $4(3-5)$ & $7,5(5-10)$ & $<0,001^{\mathrm{a}}$ \\
\hline Mortality & $0(0 \%)$ & $1(6,7 \%)$ & $8(26,7 \%)$ & $37(68,5 \%)$ & $<0,001^{\mathrm{b}}$ \\
\hline ICU admission & $0(0 \%)$ & $3(20 \%)$ & $12(40 \%)$ & $38(70,4 \%)$ & $<0,001^{\mathrm{b}}$ \\
\hline $\begin{array}{l}\text { Mechanical } \\
\text { ventilation }\end{array}$ & $0(0 \%)$ & $1(6,7 \%)$ & $1(3,3 \%)$ & $34(63 \%)$ & $<0,001^{b}$ \\
\hline \multicolumn{6}{|l|}{ Complications } \\
\hline AKI & $0(0 \%)$ & $3(20 \%)$ & $5(16,7 \%)$ & $24(44,4 \%)$ & $<0,001^{b}$ \\
\hline Septic shock & $0(0 \%)$ & $2(13,3 \%)$ & $1(3,3 \%)$ & $26(48,1 \%)$ & $<0,001^{\mathrm{b}}$ \\
\hline $\begin{array}{l}\text { Secondary } \\
\text { infection }\end{array}$ & $1(5 \%)$ & $1(6,7 \%)$ & $1(3,3 \%)$ & $23(42,6 \%)$ & $<0,001^{\mathrm{b}}$ \\
\hline
\end{tabular}

* Median (Q1-Q3); ${ }^{a}$ Analysis using Kruskal-Wallis test; ${ }^{b}$ Analysis using Chi-Square test

Subjects characteristics based on mortality were summarized in Table 2. For non survivors, length of stay were 8(4-13) days while for survivors length of stay were 20 (13-25) days. Mortality was associated with higher SOFA score, ICU admission, mechanical ventilator requirements, and complications occurred during treatment. 
Table 2. Subjects Characteristics Based on Mortality

\begin{tabular}{|c|c|c|c|}
\hline Characteristics & $\begin{array}{c}\text { Non Survivors } \\
\mathrm{N}=46\end{array}$ & $\begin{array}{c}\text { Survivors } \\
\mathrm{N}=73\end{array}$ & $\mathbf{P}$ \\
\hline Age (years)* & $53,5(44,75-63,5)$ & $52(39,5-56,5)$ & $0,041^{\mathrm{a}}$ \\
\hline Gender & & & $0,259^{b}$ \\
\hline Male & $33(71,7 \%)$ & $45(61,6 \%)$ & \\
\hline Female & $13(28,3 \%)$ & $28(38,4 \%)$ & \\
\hline BMI & & & $0,425^{\mathrm{b}}$ \\
\hline$<25$ & $18(39,1 \%)$ & $34(46,6 \%)$ & \\
\hline$\geq 25$ & $28(60,9 \%)$ & $39(53,4 \%)$ & \\
\hline \multicolumn{4}{|l|}{ Comorbidities } \\
\hline Diabetes & $20(43,5 \%)$ & $23(31,5 \%)$ & $0,186^{\mathrm{b}}$ \\
\hline Hypertension & $24(52,2 \%)$ & $20(27,4 \%)$ & $0,006^{\mathrm{b}}$ \\
\hline $\begin{array}{l}\text { Symptoms duration } \\
\text { (days)* }\end{array}$ & $7(4,75-11)$ & $7(5-9)$ & $0,596^{\mathrm{a}}$ \\
\hline Length of Stay (days)* & $8(4-13)$ & $20(13-25)$ & $<0,001^{\mathrm{a}}$ \\
\hline SOFA score D-0* & $4(4-5)$ & $2(1-3)$ & $<0,001^{\mathrm{a}}$ \\
\hline Highest SOFA score* & $8(5-11,25)$ & $3(1-4,5)$ & $<0,001^{\mathrm{a}}$ \\
\hline $\mathrm{P} / \mathrm{F}$ ratio $\mathrm{D}-0$ & $117,78(89.69-154,07)$ & $241,25(136,88-398,89)$ & $<0,001^{\mathrm{a}}$ \\
\hline ICU admission & $29(63 \%)$ & $24(32,9 \%)$ & $0,001^{\mathrm{b}}$ \\
\hline Mechanical ventilation & $31(67,4 \%)$ & $5(6,8 \%)$ & $<0,001^{\mathrm{b}}$ \\
\hline \multicolumn{4}{|l|}{ Complications } \\
\hline AKI & $22(47,8 \%)$ & $10(13,7 \%)$ & $<0,001^{\mathrm{b}}$ \\
\hline Septic shock & $25(54,3 \%)$ & $4(5,5 \%)$ & $<0,001^{\mathrm{b}}$ \\
\hline Secondary infection & $17(37 \%)$ & $9(12,3 \%)$ & $0,002^{\mathrm{b}}$ \\
\hline
\end{tabular}

* Median (Q1-Q3); ${ }^{\mathrm{a}}$ Analysis using Mann-Whitney test; ${ }^{\mathrm{b}}$ Analysis using Chi-Square test; ${ }^{\mathrm{c}}$ Analysis using Fisher's Exact Test

Subjects characteristics for patients with secondary infection were summarized in Table 3. Patients with secondary infection had longer length of stay, higher SOFA score, increased need of intensive care and mechanical ventilation, and associated with more complications, such as Acute Kidney Injury and septic shock. Positive result from blood, urine, or sputum cultures were obtained at day-5 (3-7). Most common microbes in our study were Candida albicans (7 samples;26,5\%), Candida tropicalis (6 samples;23\%), and Klebsiella pneumoniae (6 samples;23\%). Other microbes were Acinetobacter baumanii (4 samples;15,4\%), Pseudomonas aeruginosa (2 samples), Enterococcus faecalis (2 samples), Eschericia coli (2 samples), Klebsiella ozaenae, Providencia stuartii, Enterobacter cloacae, and Citrobacter koseri each 1 sample.

Table 3. Subjects Characteristics Based on Secondary Infection

\begin{tabular}{llll}
\hline \hline \multicolumn{1}{c}{ Characteristics } & $\begin{array}{c}\text { Secondary Infection } \\
\mathbf{N = 2 6}\end{array}$ & \multicolumn{1}{c}{$\begin{array}{c}\text { No Secondary } \\
\text { Infection } \\
\mathbf{N = 9 3}\end{array}$} & P \\
\hline Age(years)* & $49(43-55,25)$ & $53(42,5-59)$ & $0,552^{\mathrm{a}}$ \\
\hline $\begin{array}{l}\text { BMI } \\
<25\end{array}$ & $12(46,2 \%)$ & $40(43 \%)$ & $0,775^{\mathrm{b}}$ \\
$\geq 25$ & $14(53,8 \%)$ & $53(57 \%)$ & \\
\hline Diabetes & $13(50 \%)$ & $30(32,3 \%)$ & $0,096^{\mathrm{b}}$ \\
\hline Length of Stay (days)* & $18(12-25,25)$ & $13(7-22)$ & $0,049^{\mathrm{a}}$ \\
\hline Highest SOFA score* & $9(7,5-12)$ & $4(2-5)$ & $<0,001^{\mathrm{a}}$ \\
\hline ICU admission & $23(88,5 \%)$ & $30(32,3 \%)$ & $<0,001^{\mathrm{b}}$ \\
\hline Mechanical ventilation & $22(84,6 \%)$ & $14(15,1 \%)$ & $<0,001^{\mathrm{b}}$ \\
\hline
\end{tabular}




\begin{tabular}{llll}
\hline Complications & & & \\
AKI & $14(53,8 \%)$ & $18(19,4 \%)$ & $<0,001^{\text {b }}$ \\
Septic shock & $20(76,9 \%)$ & $9(9,7 \%)$ & $<0,001^{\text {b }}$ \\
\hline
\end{tabular}

* Median (Q1-Q3); ${ }^{\text {a }}$ Analysis using Mann-Whitney test; ${ }^{\mathrm{b}}$ Analysis using Chi-Square test

\section{Absolute Neutrophil Count (ANC), Absolute Lymphocyte Count (ALC), NLR and Procalcitonin}

ANC, ALC, NLR and procalcitonin levels from each measurement are presented in Table 4. All of these data weren't normally distributed except for ALC 2. Highest NLRs were observed at day-4(0-9). Highest PCTs were observed at day-3 (0-9).

Table 4. Serial NLR and Procalcitonin

\begin{tabular}{lcc}
\hline \hline \multicolumn{1}{c}{ Parameter } & $\begin{array}{c}\text { Median } \\
(\mathbf{Q 1 - Q 3})\end{array}$ & $\mathbf{p}^{\dagger}$ \\
\hline ANC $1\left(10^{3} / \mu \mathrm{L}\right)$ & $7,03(4,51-10,42)$ & 0,002 \\
ANC 2 $\left(10^{3} / \mu \mathrm{L}\right)$ & $10,38(6,77-18,06)$ & $<0,001$ \\
ANC 3 $\left(10^{3} / \mu \mathrm{L}\right)$ & $7,15(4,46-14,32)$ & $<0,001$ \\
\hline ALC $1\left(10^{3} / \mu \mathrm{L}\right)$ & $1,17(0,82-1,56)$ & 0,029 \\
ALC 2 $\left(10^{3} / \mu \mathrm{L}\right)$ & $1,04(0,62-1,39)$ & 0,06 \\
ALC 3 $\left(10^{3} / \mu \mathrm{L}\right)$ & $1,62(1,04-2,07)$ & 0,001 \\
\hline NLR 1 & $5,77(3,31-12,16)$ & $<0,001$ \\
NLR 2 & $12,52(5,3-26,12)$ & $<0,001$ \\
NLR 3 & $3,84(2,29-13,37)$ & $<0,001$ \\
\hline PCT 1 $(\mathrm{ng} / \mathrm{ml})$ & $0,18(0,09-0,4)$ & $<0,001$ \\
PCT 2 $(\mathrm{ng} / \mathrm{ml})$ & $0,29(0,1-1,2)$ & $<0,001$ \\
PCT 3 $(\mathrm{ng} / \mathrm{ml})$ & $0,13(0,07-0,46)$ & $<0,001$
\end{tabular}

${ }^{\dagger}$ Normality test with Kolmogorov-Smirnov, normal distribution if $\mathrm{p}>0,05$

\section{Correlation Between NLR, Procalcitonin with WHO Classification of COVID-19 Severity}

NLR and procalcitonin level for each severity class were written in Table 5. There were significant correlation between NLR and WHO severity on hospital admission $(p<0,001$; $r_{s}=0,385$-weak), on the day when highest NLR recorded ( $p<0,001 ; r_{s}=0,598$-moderate), and 24 hours before discharged from hospital $\left(\mathrm{p}<0,001 ; \mathrm{r}_{\mathrm{s}}=0,751\right.$-strong). There were significant correlation between procalcitonin and WHO severity on hospital admission $(\mathrm{p}<0,001$; $r_{s}=0,409$-moderate), on the day when highest Procalcitonin recorded $\left(p<0,001 ; r_{s}=0,508\right.$ moderate), and 24 hours before discharged from hospital ( $<<0,001 ; r_{s}=0,235$-weak).

Table 5. Correlation of NLR, Procalcitonin Levels with WHO Severity

\begin{tabular}{lcccccc}
\hline \hline Parameters & Mild & Moderate & Severe & Critical & $\mathbf{P}^{\#}$ & $\mathbf{r}_{\mathbf{s}}$ \\
\hline \hline \multirow{2}{*}{ NLR 1 } & 2,63 & 3,37 & 5,8 & 9,25 & $<0,001$ & 0,385 \\
& $(1,56-3,59)$ & $(2,35-7,03)$ & $(4,03-8,42)$ & $(5,43-16,79)$ & & \\
\hline \multirow{2}{*}{ NLR 2 } & 3,46 & 6,06 & 6,84 & 23,7 & $<0,001$ & 0,598 \\
& $(2,52-4,41)$ & $(3,63-7,21)$ & $(4,23-13,04)$ & $(14,92-$ & & \\
& & & & $36,39)$ & & \\
\hline \multirow{2}{*}{ NI R 2 } & 2,66 & - & - & 18,68 & $<0,001$ & 0,751 \\
& $(2,03-3,82)$ & & \multicolumn{7}{c}{$(9,97-26,65)$} & & \\
\hline \multirow{2}{*}{ PCT 1 } & 0,08 & 0,09 & 0,14 & 0,39 & $<0,001$ & 0,409 \\
& $(0,04-0,1)$ & $(0,08-0,29)$ & $(0,07-0,33)$ & $(0,17-0,71)$ & & \\
\hline PCT 2 & 0,1 & 0,1 & 0,2 & 1,07 & $<0,001$ & 0,508 \\
\hline
\end{tabular}




\begin{tabular}{lcccccc}
\hline & $(0,07-0,15)$ & $(0,08-0,18)$ & $(0,12-0,35)$ & $(0,3-4,52)$ & & \\
\hline DCT 2 & 0,08 & - & - & 0,66 & 0,01 & 0,235 \\
& $(0,05-0,13)$ & & & $(0,2-2,59)$ & & \\
\hline
\end{tabular}

\#Analysis using Spearman Test

ROC curve analysis was used to analyze NLR and procalcitonin levels to obtain a cutoff value to predict severe-critical illness. We used NLR 2 (highest NLR) and PCT 2 (highest procalcitonin) because its correlation $\left(\mathrm{r}_{\mathrm{s}}\right)$ was stronger than NLR and procalcitonin on hospital admission. Cutoff value of NLR $>6,82$ can predict severe-critical illness (AUC=0,905) with sensitivity $82,2 \%$ and specificity 82,8\% (Figure 1 A). Relative Risk 2,342 CI 95\% 1,595-3,438. Cutoff value of Procalcitonin $>0,145 \mathrm{ng} / \mathrm{ml}$ can predict severe-critical illness (AUC 0,857) with sensitivity 82,6\% and spesificity 75,8\% (Figure 1B). Relative Risk 2,397 CI 95\% 1,596-3,600.
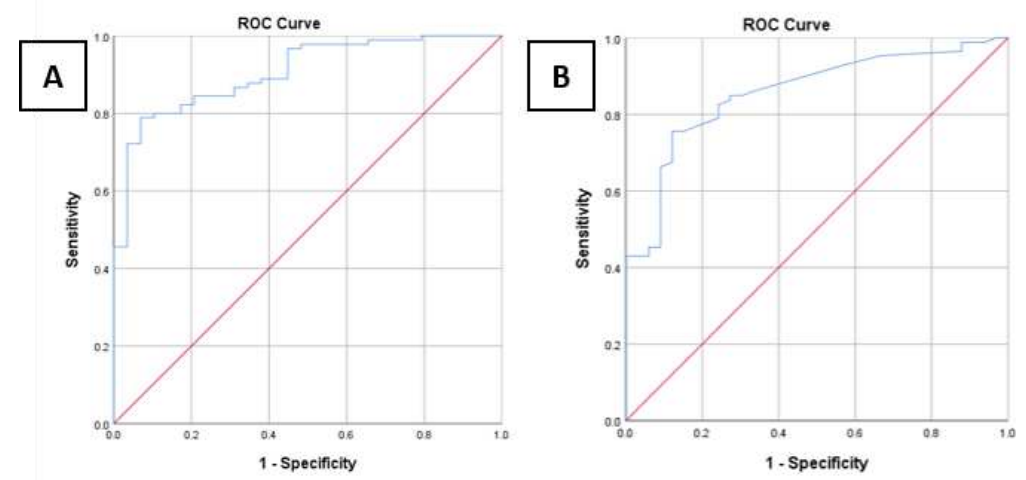

Figure 1 ROC Curve of NLR (A) and procalcitonin (B) as Critical Ilness Predictor

\section{Correlation Between NLR or Procalcitonin with SOFA score}

In this study, NLRs were correlated significantly with SOFA score on hospital admission ( $\mathrm{p}<0,001 ; \mathrm{r}_{\mathrm{s}}=0,549$-moderate), on the day when highest NLR recorded $(\mathrm{p}<0,001$; $r_{s}=0,683$-strong), and 24 hours before discharged from hospital ( $<<0,001 ; r_{s}=0,782$-strong). There were significant correlation between procalcitonin levels and SOFA score on hospital admission $\left(\mathrm{p}<0,001 ; \mathrm{r}_{\mathrm{s}}=0,574\right.$-moderate $)$, on the day when highest procalcitonin recorded $\left(\mathrm{p}<0,001 ; \mathrm{r}_{\mathrm{s}}=0,716\right.$-strong), and 24 hours before discharged from hospital $\left(\mathrm{p}<0,001 ; \mathrm{r}_{\mathrm{s}}=0,679\right.$ strong). Spearman test was used for analysis.

\section{Comparison of NLR and Procalcitonin Between Non Survivor vs Survivor}

NLR and procalcitonin levels for non survivor vs survivor were presented in Table 6. There were significant difference of NLR between survivor and non survivor on hospital admission, on the day when highest NLR recorded, and 24 hours before discharged from hospital $(p<0,001)$. There were also significant difference of procalcitonin between survivor and non survivor on hospital admission, on the day when highest procalcitonin recorded, and 24 hours before discharged from hospital $(p<0,001)$. Mann-Whitney test was used for analysis.

Table 6. NLR and procalcitonin levels in survivor vs non survivor

\begin{tabular}{lccc}
\hline Parameters & Non survivor & Survivor & P $\ddagger$ \\
\hline NLR 1 & $10,32(4,53-19,6)$ & $4,77(2,67-7,81)$ & $<0,001$ \\
NLR 2 & $25,17(12,99-42,01)$ & $7,21(3,95-15,99)$ & $<0,001$ \\
NLR 3 & $18,68(9,97-26,65)$ & $2,66(2,03-3,82)$ & $<0,001$ \\
PCT 1 & $0,3(0,06-0,29)$ & $0,1(0,06-0,29)$ & $<0,001$ \\
PCT 2 & $1,15(0,32-4,30)$ & $0,16(0,1-0,4)$ & $<0,001$ \\
PCT 3 & $0,66(0,2-2,59)$ & $0,08(0,05-0,13)$ & $<0,001$ \\
\hline
\end{tabular}


†Analysis using Mann-Whitney Test

ROC curve analysis was used to analyze NLR and procalcitonin levels to obtain a cutoff value to predict mortality. We used cuttoff value of NLR $>12,75$ as mortality predictor with AUC 0,782, sensitivity 78,3\% and specificity 68,5\%. Relative Risk 3,661 CI 95\% 2,006-6,680. Cutoff value of Pct $>0,285 \mathrm{ng} / \mathrm{ml}$ can predict mortality with AUC 0,789 sensitivity 80,4\% specificity 68,5\%. Relative Risk 4,043 CI 95\% 2,145-7,618.
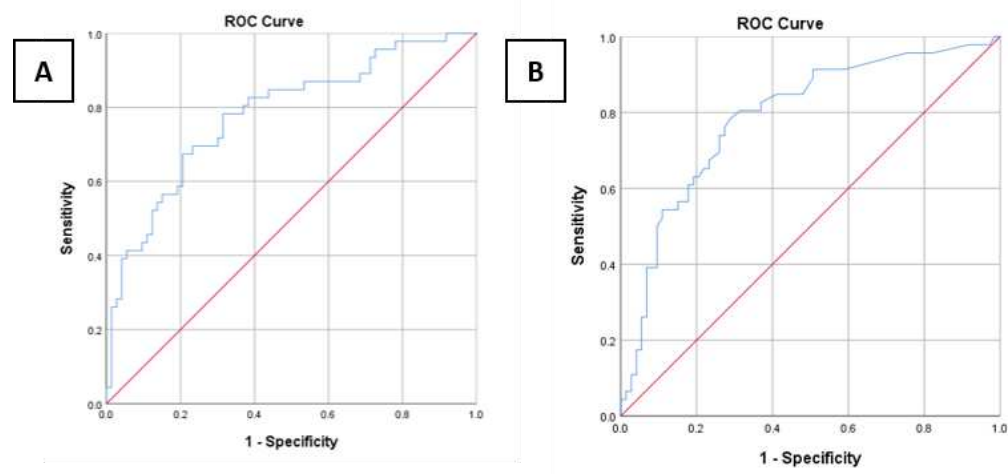

Figure 2 ROC Curve of NLR (A) and procalcitonin (B) as Mortality Predictor

\section{Comparison of NLR or procalcitonin Between Patients With or Without Secondary Infection}

Highest NLRs were observed at day-4(0-9). Highest PCTs were observed at day-3 (09). Positive result from blood, urine, or sputum cultures were obtained at day-5 (3-7), therefore secondary infection clinically occurred before.

In this study, patients with secondary infection had higher NLR and procalcitonin than patients without secondary infection (Table 7). There were significant difference of NLR between patients with secondary infection and patients without secondary infection $(p<0,001)$. There were also significant difference of procalcitonin between patients with secondary infection and patients without secondary infection $(\mathrm{p}<0,001)$.

Table 7. NLR and procalcitonin levels in Patients with Secondary Infection vs No Secondary Infection

\begin{tabular}{lccc}
\hline & Secondary infection & $\begin{array}{c}\text { No Secondary } \\
\text { Infection }\end{array}$ & P*** \\
\hline $\begin{array}{l}\text { Highest } \\
\text { NLR }\end{array}$ & $26,63(18,30-42,01)$ & $8,68(4,18-19,78)$ & $<0,001$ \\
$\begin{array}{l}\text { Highest } \\
\text { PCT }\end{array}$ & $1,91(0,95-6,68)$ & $0,18(0,1-0,44)$ & $<0,001$ \\
$* *$ Analysis using Mann-Whitney Test & & \\
\end{tabular}

\section{DISCUSSION}

\section{Characteristics of Research Subjects}

Patients in severe-critical and non survivor groups were older. Aging process is associated with changes in distribution and competence of immune cells. This aging related changes begin at 
the sixth decades of life. Weakened adaptive immunity leaving older individuals susceptible to infection. The diversity of T-cell declines, it affects immune system to specifically recognize antigen. A major defect in older T cells is inability to properly repair damaged DNA (9). Most of severe and critical patients were male. Male have higher plasma ACE-2 levels than female, this may lead to higher expression of ACE-2 receptors which has a role in SARS-CoV-2 infection. Another reason, the $\mathrm{X}$ chromosome has a high density of immune-related gene, therefore, women have stronger innate and adaptive immune responses. Differences in immune response can also be caused by sex hormones, such as estrogen, progesterone, and androgens (10).

Hypertension was the most common comorbidities in this study. Several studies showed that anti hypertensive drugs such as ACE inhibitor and angiotensin receptor blockers are associated with increased expression of ACE2 on cell membrane, therefore SARS-CoV-2 virus is easier to infect cells. Other possibility, hypertensive patients have decreased expression of ACE2, while SARS-CoV-2 will be bound to ACE2 receptor. This will lead to increased level of Angiotensin 2 which has important role in COVID-19 disease progression (11).

On hospital admission, Absolute Neutrophil Count (ANC) was 7,03 (4,51-10,42) x $10^{3} / \mu \mathrm{L}$ and Absolute Lymphocyte Count (ALC) was $1,17(0,82-1,56) \times 10^{3} / \mu \mathrm{L}$. Normal ANC is $2,5-8 \times 10^{3} / \mu \mathrm{L}$ and normal ALC is $1-4 \times 10^{3} / \mu \mathrm{L}$ (12). Normal NLR is $0,78-3,53$ in adults (13). ANC continued to rise until 10,38 $(6,77-18,06)$ while ALC were not so different $[1,04$ $(0,62-1,39)]$ on the day when highest NLR was recorded. ANC decreased and ALC increased 24 hours before discharge, and NLR decreased to almost within normal limit.

Neutrophil recruitment is part of immune response which caused by SARS-CoV-2 infection. SARS-CoV-2 infection on respiratory tract triggers various cytokines, chemokines. CXCL-8 is chemokines which facilitates neutrophil recruitment to infection site. Even though neutrophils have protective roles, activation of these cells for extensive and long term in lungs brings can cause Acute Respiratory Disease Syndrome (14). SARS-CoV-2 infection can cause exhaustion of $\mathrm{T}$ cells. There is increased expression of programmed cell death protein-1 (PD1) and $\mathrm{T}$ cell immunoglobulin and mucin domain 3 (Tim-3) which correlates with disease severity and the needs for intensive care. Other possibility, SARS-CoV-2 is able to infect T cells, but it still needs further research (15). Other factors which can contributes to increased NLR in this study is $57 \%$ of patients was overweight and obese. Obesity is associated with chronic inflammation, which can increase NLR (16).

Dr Soetomo is a referral hospital for Eastern part of Indonesia, therefore most of patients of this study $(45,4 \%)$ belong to critical group. This will affect number of complications, mortality, needs of intensive care and mechanical ventilation. Secondary infection occurred to $26(21,8 \%)$ patients in this study. The most common findings were Candida albicans, Candida tropicalis, Klebsiella pneumoniae, and Acinetobacter baumanii. In previous study from China, Acinetobacter baumanii and Klebsiella pneumoniae were also found in cultures from COVID19 patients (16).

\section{Correlation Between NLR or Procalcitonin with COVID-19 Severity and Secondary Infection}

There were significant correlations between NLR and COVID-19 severity (WHO classification and SOFA score) at hospital admission, at the day when highest NLR was recorded, and 24 hours before hospital discharge. Cutoff value of NLR >6,82 used as severecritical illness predictor. Patients with NLR $>6,82$ were 2,342 times more likely to develop severe-critical illness than patients with $\operatorname{NLR} \leq 6,82$. This cutoff value can be used for 
screening. High risk patients might be better to be treated early in intensive care unit and receive more aggressive treatment.

NLR is calculated from ANC and ALC. In this study ANC was higher and ALC was lower in severe and critical group, therefore NLR is higher. This finding supports previous study that neutrophil is significantly increased in severe COVID-19 patients (17). NLR continued to increase as disease progression in critical patients. 24 hours before hospital discharge, patients who died (critical group) has high NLR, while patients who survived had normal NLR.

High NLR is an indicator of imbalance immune response with increased neutrophil and decreased lymphocyte. COVID-19 severity is mainly affected by innate immune response. Cytokine storm occurred in severe patients, a condition with exaggerated immune response. Inflammation factors production in viral infection, such as Interleukin-6, Interleukin-8, and granulocyte colony-stimulating factor, can trigger neutrophil production. In the other hand, systemic inflammation can cause faster lymphocyte apoptosis and decreased cellular immunity (18). Other possible cause of increased NLR in severe and critical patients is secondary infection. NLR in secondary bacterial infection is higher than NLR in viral infection (19).

There were significant correlations between procalcitonin and COVID-19 severity ( WHO classification and SOFA score) at hospital admission, at the day when highest procalcitonin was recorded, and 24 hours before hospital discharge. Patients in severe and critical group had higher procalcitonin. Procalcitonin is 116 amino acid precursor from calcitonin, which is produced by thyroid $\mathrm{C}$ cells. Bacterial infection triggers inflammatory reaction and leucocyte recruitment to infection site. Microbes products like lipopolysaccharides and pro inflammatory mediators (IL-1 $\beta$, TNF- $\alpha$ ) impair tissue selective expression in differentiated parenchymal cells. Calcitonin(CT)-mRNA induction cause massive secretion of several calcitonin precursors, including procalcitonin into circulation. In sepsis, parenchymal cells from specific organ (adipocyte, liver, lung, brain, muscle cells) have important roles in procalcitonin release (20).

Highest NLRs were observed at day-4(0-9). Highest procalcitonin were observed at day-3 (0-9). Positive result from blood, urine, or sputum cultures were obtained at day-5 (3-7), therefore secondary infection clinically occurred before. Highest procalcitonin in critical patients were markedly increased $1,07(0,3-4,52) \mathrm{ng} / \mathrm{ml}$. In this study, secondary infection occurred in 3,3\% of severe patients and $42,6 \%$ of critical patients. Virus impairs mucociliary clearance function, therefore bacteria is easier to attach and colonize. Viral infection cause desensitization in lung sentinel cells to TLR signal which contributes to secondary bacterial infection (21). Moreover, 63\% patients in critical group treated with mechanical ventilation, with the risk of Ventilator Associated Pneumonia (VAP). Previous study in China, secondary infection occurred in 20\% severe COVID-19 patients and 50\% critical COVID-19 patients (22).

Most common microbes found in cultures in this study is Candida albicans and Candida tropicalis. Previous study by Cortegiani et al. (2014) comparing procalcitonin in bacterial infection and fungal infection found that procalcitonin in Candida species infection was lower $[0,99(0,86-1,34) \mathrm{ng} / \mathrm{ml}]$ than in bacterial infection $[16,7(7,65-50,2) \mathrm{ng} / \mathrm{ml}]$ or mixed bacterial and Candida infection $[4,76(2,98-6,08) \mathrm{ng} / \mathrm{ml}]$. Sepsis is a complex immune response against pathogens, with hyperinflammatory phase as a hallmark in early period followed by impaired immunity phase and anti inflammatory predominance. The reason why procalcitonin is lower probably because infection is occurred in that impaired immunity phase (23). Another 
possibility is fungal infection has different pattern of cytokine response compared to bacterial infection (24). Therefore, we should be aware of fungal infections in COVID-19.

Fungal infection in COVID-19 should be worried about, especially in severe and critical group. In severe COVID-19 patients, CD4+ and CD8+ T cells is decreased significantly compared to non severe patients (25). CD4+ and CD8+ T cells have important roles in adaptive immune response to protect against fungal infection (26). Candidiasis is the main cause of fungal infection in intensive care unit, with candida albicans as the most common cause. Factors associated with severe fungal infection are mucosal damage, immunosuppression, diabetes, medical procedures such as central vein catheter, total parenteral nutrition, and medical workers' poor hygiene. Fungal cultures have long incubation period, and sometimes negative result in deep sited candidiasis. Anti fungal therapy should be started when there is yeast found in culture without any delay to wait for species identification (27).

\section{Comparison of NLR or Procalcitonin Between Non Survivor vs Survivor}

In this study, there were significant NLR difference in mortality groups at the hospital admission, at the time when highest NLR was recorded, and 24 hours before hospital discharge. Patients who were not survive had higher ANC and lower ALC, therefore higher NLR.

COVID-19 is associated with multiple organ involvement such as lung, liver, kidney, heart, gastrointestinal, hematology, and neurology system. Multiple organ failure in COVID19 is associated with higher mortality (28). In this study, patients who were not survive had higher SOFA score (Table 2). Artery and vein endothel in various organs are able to express ACE2. Microscopic finding of SARS-CoV-2 virus particle in lung and kidney endothelial cells support those finding. Endothelial damage and endothelialitis (marked by activated macrophage and neutrophil) are found in lung, kidney, liver, intestines, and heart of COVID19 patients. This leads to thrombin production, fibrinolysis inhibition, and complement system activation, starts thromboinflammation process which cause microthrombi deposition and microvascular disfunction. Cross communication between neutrophil and platelet along with macrophage activation cause proinflammatory effects, such as cytokine release, neutrophil extracellular traps (NETS) formation, fibrin, and microthrombi. NETs will cause further endothelial damage (29).

High NLR is associated with pro inflammatory cytokine production. During this pandemic, a lot of research about drugs or intervention for severe COVID-19 patients, including how to deal with cytokine storm. RECOVERY Clinical Trial studied dexamethasone treatment for COVID-19. Mortality in patients with dexamethasone treatment was lower for patients with mechanical ventilation or other types of oxygen support (30). Other drug is specific cytokine inhibitor, like IL-1 receptor antagonist (Anankira), anti IL-6 receptor monoclonal antibody (Tocilizumab), said can reduce needs for mechanical ventilation. Non pharmacology intervention, such as continuous renal replacement therapy (CRRT) as hemofiltration for pro inflammatory cytokines clearance. Another method is therapeutic plasma exchange (TPE), in several COVID-19 studies found that it could decrease IL-6 and ferritin level with clinical improvement, and decrease mortality in patients with respiratory failure (31).

Procalcitonin in this study was significantly different between survivors and non survivors. Procalcitonin levels were higher in non survivor group. Increased level in procalcitonin is associated with secondary bacterial infection (32). Procalcitonin $>0,5 \mathrm{ng} / \mathrm{ml}$ is usually used to diagnose bacterial infecti 
Steroid as one of COVID-19 treatment could increase secondary infection both bacterial and fungal (33). In this study, 63\% patients of non survivor group were in intensive care unit, and $67,4 \%$ patients need mechanical ventilation, and 54,3\% suffered from septic shock. In $2009 \mathrm{H} 1 \mathrm{~N} 1$ pandemic, 30\% of critical ill patients were diagnosed with bacterial pneumonia or bacteriemia 72 hours after intensive care unit admission (4). COVID-19 patients needed long term ventilatory support, therefore possibility of hospital or ventilator acquired infection is higher (34). A lot of patients in intensive care unit need urine catheter, CRRT, ECMO, and tracheostomy. These can also contributes to hospital acquired infection (35). Secondary bacterial infection on viral infection increase severity and mortality (34).

Secondary infection prevention is very important in COVID-19, especially in severe and critical patients. Cleaning patients' environment routinely can reduce risk of hospital acquired infections. Contaminated hands of medical worker contribute to 30-40\% of hospital acquired infections (36), therefore hand hygiene and gloves changing are important during patient care. Aseptic technique in invasive device insertion, such as urine catheter, arterial line, and central vein catheter and routine care of those devices can reduce risk of infection (37). Good glycemic control can reduce mortality in infection, because uncontrolled hyperglycemia can increase risk of impaired cellular immunity function (38).

There were some limitations in this study, this study was single-centered and retrospective, most of patients were severe and critical patients, and symptoms duration at hospital admission was various.

\section{CONCLUSIONS}

NLR and procalcitonin significantly correlates with COVID-19 severity, both in WHO classification and SOFA score. NLR >6,82 can be used as predictor for severe-critical COVID19. Procalcitonin $>0,145 \mathrm{ng} / \mathrm{ml}$ can be used as predictor for severe-critical COVID-19. There are significant difference of NLR and procalcitonin between mortality groups of COVID-19 patients. NLR> 12,75 can be used as mortality predictor for COVID-19. Cutoff value of Procalcitonin $>0,285 \mathrm{ng} / \mathrm{ml}$ can predict mortality in COVID-19. There are significant difference of NLR and procalcitonin between COVID-19 patients with secondary infection.

\section{REFERENCES}

1. WHO. WHO Coronavirus (COVID-19) Dashboard [Internet]. 2021 [cited 2021 Dec 25]. Available from: https://covid19.who.int/

2. Rodriguez-Morales AJ, Cardona-Ospina JA, Gutiérrez-Ocampo E, Villamizar-Peña R, Holguin-Rivera Y, Escalera-Antezana JP, et al. Clinical, laboratory and imaging features of COVID-19: A systematic review and meta-analysis. Travel Med Infect Dis . 2020;34(March):101623.

3. Mallia P, Johnston SL. Influenza infection and COPD. Int J COPD. 2007;2(1):55-64.

4. Rice TW, Rubinson L, Uyeki TM, Vaughn FL, John BB, Miller RR, et al. Critical illness from 2009 pandemic influenza A virus and bacterial coinfection in the United States*. Crit Care Med. 2012 May;40(5):1487-98.

5. Farkas J. COVID-19 - EMCrit Project. Internet B Crit Care. 2020;1-24.

6. Lippi G, Cervellin G. Procalcitonin for diagnosing and monitoring bacterial infections: 
For or against? Clin Chem Lab Med. 2018;56(8):1193-5.

7. Singer M, Deutschman C, Seymour CW, Shankar-Hari M, Annane D, Bauer M, et al. The Third International Consensus Definitions for Sepsis and Septic Shock (Sepsis-3). 2016;315(8):801-10.

8. WHO. Clinical Management of COVID-19. Interim Guidance 27 May 2020. World Heal Organ. 2020;1-55.

9. Weyand CM, Goronzy JJ. Aging of the Immune System. Mechanisms and Therapeutic Targets. Ann Am Thorac Soc. 2016 Dec;13(Supplement_5):S422-8.

10. Griffith DM, Sharma G, Holliday CS, Enyia OK, Valliere M, Semlow AR, et al. Men and COVID-19: A biopsychosocial approach to understanding sex differences in mortality and recommendations for practice and policy interventions. Prev Chronic Dis. 2020;17:1-9.

11. Du Y, Zhou N, Zha W, Lv Y. Hypertension is a clinically important risk factor for critical illness and mortality in COVID-19: A meta-analysis. Nutr Metab Cardiovasc Dis. 2021;31(3):745-55.

12. Pagana KD, Pagana TN, Pagana TJ. Mosby's Diagnostic and Laboratory Test Reference. 14th editi. Elsevier; 2018.

13. Forget $\mathrm{P}$, Khalifa C, Defour JP, Latinne D, Van Pel MC, De Kock M. What is the normal value of the neutrophil-to-lymphocyte ratio? BMC Res Notes. 2017;10(1):1-4.

14. Cavalcante-Silva LHA, Carvalho DCM, Lima É de A, Galvão JGFM, da Silva JS d. F, Sales-Neto JM de, et al. Neutrophils and COVID-19: The road so far. Int Immunopharmacol. 2021;90(January).

15. Tavakolpour S, Rakhshandehroo T, Wei EX, Rashidian M. Lymphopenia during the COVID-19 infection: What it shows and what can be learned. Immunol Lett Elsevier. 2020;225(January):19-21.

16. Chen N, Zhou M, Dong X, Qu J, Gong F, Han Y, et al. Epidemiological and clinical characteristics of 99 cases of 2019 novel coronavirus pneumonia in Wuhan, China: a descriptive study. Lancet. 2020;395(10223):507-13.

17. Liu J, Liu Y, Xiang P, Pu L, Xiong H, Li C, et al. Neutrophil-to-lymphocyte ratio predicts critical illness patients with 2019 coronavirus disease in the early stage. J Transl Med. 2020;18(1).

18. Simadibrata DM, Calvin J, Wijaya AD, Arkan N, Ibrahim A. Neutrophil-to-lymphocyte ratio on admission to predict the severity and mortality of COVID-19 patients: A metaanalysis. 2020;(January).

19. Naess A, Nilssen SS, Mo R, Eide GE, Sjursen H. Role of neutrophil to lymphocyte and monocyte to lymphocyte ratios in the diagnosis of bacterial infection in patients with fever. Infection. 2017;45(3):299-307.

20. Christ-Crain M, Müller B. Biomarkers in respiratory tract infections: Diagnostic guides to antibiotic prescription, prognostic markers and mediators. Eur Respir J. 2007;30(3):556-73.

21. Akira S, Uematsu S, Takeuchi O. Pathogen recognition and innate immunity. Cell. 
2006;124(4):783-801.

22. Hu R, Han C, Pei S, Yin M, Chen X. Procalcitonin levels in COVID-19 patients. Int J Antimicrob Agents. 2020 Aug;56(2):106051.

23. Cortegiani A, Russotto V, Montalto F, Foresta G, Accurso G, Palmeri C, et al. Procalcitonin as a marker of Candida species detection by blood culture and polymerase chain reaction in septic patients. BMC Anesthesiol. 2014 Dec 21;14(1):9.

24. Charles PE, Dalle F, Aho S, Quenot J-P, Doise J-M, Aube H, et al. Serum procalcitonin measurement contribution to the early diagnosis of candidemia in critically ill patients. Intensive Care Med. 2006 Sep 29;32(10):1577-83.

25. Zhang $\mathrm{H}, \mathrm{Wu} \mathrm{T}$. CD4+T, CD8+T counts and severe COVID-19: A meta-analysis. J Infect. 2020 Sep;81(3):e82-4.

26. Kumaresan PR, da Silva TA, Kontoyiannis DP. Methods of controlling invasive fungal infections using CD8+ T cells. Front Immunol. 2018;8(DEC):1-14.

27. Matthaiou DK, Christodoulopoulou T, Dimopoulos G. How to treat fungal infections in ICU patients. BMC Infect Dis. 2015;15(1):1-8.

28. Mokhtari T, Hassani F, Ghaffari N, Ebrahimi B, Yarahmadi A, Hassanzadeh G. COVID19 and multiorgan failure: A narrative review on potential mechanisms. J Mol Histol. 2020;51(6):613-28.

29. Gupta A, Madhavan M V., Sehgal K, Nair N, Mahajan S, Sehrawat TS, et al. Extrapulmonary manifestations of COVID-19. Nat Med. 2020;26(7):1017-32.

30. Horby P, Lim WS, Emberson JR, Mafham M, Bell J, Linsell L, et al. Dexamethasone in Hospitalized Patients with Covid-19. N Engl J Med. 2021 Feb 25;384(8):693-704.

31. Kim JS, Lee JY, Yang JW, Lee KH, Effenberger M, Szpirt W, et al. Immunopathogenesis and treatment of cytokine storm in COVID-19. Theranostics. 2021;11(1):316-29.

32. Matsumura Y, Nakada TA, Abe R, Oshima T, Oda S. Serum procalcitonin level and SOFA score at discharge from the intensive care unit predict post-intensive care unit mortality: A prospective study. PLoS One. 2014;9(12):1-13.

33. Obata R, Maeda T, Rizk D, Kuno T. Increased Secondary Infection in COVID-19 Patients Treated with Steroids in New York City. Jpn J Infect Dis. 2021 Jul 31;74(4):JJID.2020.884.

34. Cox MJ, Loman N, Bogaert D, O'Grady J. Co-infections: potentially lethal and unexplored in COVID-19. The Lancet Microbe. 2020;1(1):e11.

35. Zhang H, Zhang Y, Wu J, Li Y, Zhou X, Li X, et al. Risks and features of secondary infections in severe and critical ill COVID-19 patients. Emerg Microbes Infect. 2020;9(1):1958-64.

36. Doll M, Stevens M, Bearman G. Environmental cleaning and disinfection of patient areas. Int J Infect Dis. 2018 Feb;67:52-7.

37. O'Grady NP, Alexander M, Burns LA, Dellinger EP, Garland J, Heard SO, et al. Guidelines for the Prevention of Intravascular Catheter-related Infections. Clin Infect Dis. 2011 May 1;52(9):e162-93. 
38. Butler SO, Btaiche IF, Alaniz C. Relationship Between Hyperglycemia and Infection in Critically Ill Patients. Pharmacotherapy. 2005 Jul;25(7):963-76. 